\title{
OS NOVOS RUMOS DA MEDIAÇÃO NO BRASIL
}

NEW DIRECTIONS IN MEDIATION IN BRAZIL

Mariana Alves Lara*

\begin{abstract}
Resumo:
O presente trabalho busca analisar as recentes alterações introduzidas pelo novo Código de Processo Civil e pela Lei n. 13.105 de 2015 no tocante à mediação. Para tanto, parte-se da definição de mediação como meio complementar e consensual de resolução de controvérsias, destacando suas principais características. Após um breve histórico acerca da regulamentação da mediação no Brasil e da tendência mundial, serão tratadas as novas regras que passarão a disciplinar o instituto para, ao final, concluir que foi dado um importante passo no Brasil em direção à cultura de pacificação dos conflitos.
\end{abstract}

Palavras-chave: Mediação. Novo Código de Processo Civil. Lei de Mediação.

\begin{abstract}
:
This paper analyzes the recent changes introduced by the new Civil Procedure Code and by the Law No. 13,105/2015 regarding mediation. Therefore, the analysis starts from the definition of mediation as a complementary and consensual mechanism of dispute resolution, highlighting its key features. After a brief history about the regulation of mediation in Brazil and the world trend, the new rules of the institute will be analyzed. In the end, will conclude that it was an important step in Brazil towards the culture of pacification of conflicts.
\end{abstract}

Keywords: Mediation. New Civil Procedure Code. Mediation Law.

\section{Introdução}

Em 17 de março de 2015 foi publicada a Lei n. 13.105 que institui um novo Código de Processo Civil no Brasil. Essa nova lei teve vacatio legis de um ano contado da data de sua publicação oficial (art. 1.045), entrando em vigor em 18 de março de $2016 .{ }^{1}$

Doutoranda em Direito Civil na Universidade de São Paulo; mestre e bacharel em Direito pela Universidade Federal de Minas Gerais; professora de Direito Civil na Faculdade Milton Campos.

1 Tendo em vista a controvérsia no meio jurídico quanto à data correta do início da vigência do Novo Código de Processo Civil, o Pleno do Superior Tribunal de Justiça, de forma unânime, resolveu definir o dia 18 de março de 2016 como o início de vigência. Disponível em: <http://www.stj.jus.br/sites/STJ/default/pt_BR/ Comunica\%C3\%A7\%C3\%A3o/Not\%C3\%ADcias/Not\%C3\%ADcias/Pleno-do-STJ-define-que-o-novoCPC-entra-em-vigor-no-dia-18-de-mar\%C3\%A7o $>$. Acesso em: 15 maio 2016. Dessa forma, aplicou-se o art. $8^{\circ}, \S 1^{\circ}$, da Lei Complementar 95/98 que dispõe: "A contagem do prazo para entrada em vigor das leis que estabeleçam periodo de vacância far-se-á com a inclusão da data da publicação e do último dia do prazo, entrando em vigor no dia subsequente à sua consumação integral". Desta forma, considerando que o novo Código de Processo Civil foi publicado em 17/3/2015, o período de vacância seria até 17/3/2016, de modo que, corretamente, entrou em vigor no dia subsequente, qual seja, 18/3/2015. 
Dentre as inovações do novo Código de Processo Civil, ganharam destaque os mecanismos extrajudiciais de resolução de controvérsias, como a arbitragem, a mediação e a conciliação. $\mathrm{O}$ art. $3^{\circ}, \S 3^{\circ}$ determina que os métodos de solução consensual sejam estimulados por todos os agentes do processo. ${ }^{2}$

Logo após a aprovação do novo CPC, foi também aprovada a primeira lei brasileira a regulamentar a mediação, a Lei n. 13.140, de 2 de junho de 2015, que entrou em vigor após decorridos cento e oitenta dias de sua publicação (art. 47).

Neste contexto, verifica-se a tentativa do legislador de estruturar um modelo multiportas para a resolução de conflitos no Brasil, no qual seja agregado à tradicional jurisdição, mecanismos complementares. Ou seja, o Estado assumiu o papel de incentivar outras vias para a resolução de litígios que não passem por uma decisão judicial.

A busca por métodos alternativos se insere em um cenário de enorme congestionamento de demandas no Poder Judiciário, o que leva inexoravelmente a uma maior morosidade no julgamento e, por consequência, à insatisfação dos jurisdicionados. Segundo o relatório elaborado pelo Conselho Nacional de Justiça, o Poder Judiciário iniciou o ano de 2014 com um estoque de 70,8 milhões de processos. Este número aumentou desde então, uma vez que a quantidade de processos baixados é menor que o ingresso de novos casos. Desta forma, a taxa de congestionamento do Poder Judiciário em 2014 foi de $71,4 \%$, com aumento de 0,8 ponto percentual em relação ao ano anterior. Também consta no relatório que, mesmo se o Poder Judiciário fosse paralisado sem ingresso de novas demandas, levando em consideração a atual produtividade de magistrados e servidores, seriam necessários quase dois anos e meio de trabalho para zerar o estoque. ${ }^{3}$

A esta preocupação com o acúmulo de demandas no Poder Judiciário, soma-se o despertar para o fato de que quase nunca a decisão proferida pelo magistrado ou pelo árbitro é satisfatória para ambas as partes. Ou seja, nas formas de heterocomposição dos litígios, em que a decisão é proferida por um terceiro (jurisdição e arbitragem), haverá uma parte ganhadora e outra perdedora. Não raras vezes, a decisão não é boa para nenhum dos envolvidos, que sairão ambos perdedores. Em contrapartida, por meio dos métodos consensuais de resolução de controvérsias (autocomposição), dentre os quais se destacam

2 Art. 3ํNão se excluirá da apreciação jurisdicional ameaça ou lesão a direito.

$\S 1^{\circ}$ É permitida a arbitragem, na forma da lei.

$\S$ 2ㅇ Estado promoverá, sempre que possível, a solução consensual dos conflitos.

§ 3ํA conciliação, a mediação e outros métodos de solução consensual de conflitos deverão ser estimulados por juízes, advogados, defensores públicos e membros do Ministério Público, inclusive no curso do processo judicial.

3 CONSELHO NACIONAL DE JUSTIÇA. Justiça em números 2015: ano-base 2014. Brasília: CNJ, 2015. p. 34 . 
a mediação e a conciliação, é possível que os próprios envolvidos construam uma solução ao litígio, auxiliados por um terceiro facilitador, de modo que todos sairão vencedores.

Gladys Álvarez et alii apontam como vantagens em se adotar novos mecanismos de resolução de controvérsias, a rapidez na solução do litígio; a confidencialidade do procedimento; o menor formalismo e a maior flexibilidade; a justiça da decisão, que se amoldará às necessidades das partes e os menores custos. ${ }^{4}$

Como esclarece Kazuo Watanabe, é preciso aceitar que "os chamados meios alternativos de resolução de controvérsia constituem um capítulo importante do Direito Processual Civil, e não um mero apêndice dele para ser estudado em disciplina coadjuvante". 5

Alexandre de Freitas Câmara vai além e afirma que o Poder Judiciário é que deve ser o meio alternativo de resolução de controvérsias. Segundo o autor, a sociedade deve ser capaz de solucionar por si só, de maneira pacífica, os conflitos jurídicos que nela surjam, reservando ao Poder Judiciário apenas aqueles casos em que os meios adequados de solução não foram capazes de resolver. ${ }^{6}$

Por óbvio, não se busca eliminar ou minorar o papel do Poder Judiciário. Algumas demandas só podem ser decididas pelo juiz, seja porque as partes assim desejam, seja pela própria natureza do conflito. Por isso, acredita-se ser mais adequado falar em métodos complementares de resolução de controvérsia, uma vez que as técnicas consensuais serão empregadas em conjunto com os mecanismos adversariais.

O professor Cândido Rangel Dinamarco esclarece que, graças à "soberania de que seu poder é dotado, reserva-se o Estado a capacidade de ditar a última palavra sobre todo conflito", todavia, "a exagerada valorização da tutela jurisdicional estatal, a ponto de afastar ou menosprezar o valor de outros meios de pacificar, constitui desvio de perspectiva a ser evitado". ${ }^{7}$

Neste contexto de valorização e incentivo dos meios complementares de resolução de controvérsias, sobretudo dos meios consensuais, o presente trabalho

4 ÁlVAREZ, Gladys Stella; HIGHTON, Elena Inés; JASSAN, Elías. Mediación y Justicia. Buenos Aires: Depalma, 1996. p. 40.

5 WATANABE, Kazuo. Política judiciária nacional de tratamento adequado dos interesses em conflito. Utilização dos meios alternativos de resolução de controvérsias. In: MENDES, Aluisio Gonçalves de Castro; WAMBIER, Teresa Arruda Alvim. (Org.) O processo em perspectiva: Jornadas Brasileiras de Direito Processual - Homenagem a José Carlos Barbosa Moreira. São Paulo: Revista dos Tribunais, 2013. p. 241-245. p. 242.

6 CÂMARA, Alexandre Freitas. Mediação e conciliação na Res. 125 do CNJ e no Projeto de Código de Processo Civil. In: MENDES, Aluisio Gonçalves de Castro; WAMBIER, Teresa Arruda Alvim. (Org.) $O$ processo em perspectiva: Jornadas Brasileiras de Direito Processual - homenagem a José Carlos Barbosa Moreira. São Paulo: Revista dos Tribunais, 2013. p. 39-45. p. 40.

7 DINAMARCO, Cândido Rangel. Instituições de direito processual civil. 7. ed. rev. São Paulo: Malheiros, 2013. v. 1. p. 121-122. 
pretende analisar as recentes mudanças introduzidas no Direito Processual brasileiro no tema concernente à mediação, sobretudo a partir da promulgação do novo Código de Processo Civil e da Lei de Mediação, avaliando os novos rumos do instituto.

2. O que é mediação

2.1. Visão Positiva do Conflito

"Não devemos ter medo dos confrontos... Até os planetas se chocam e do caos nascem as estrelas". (Charles Chaplin)

Para se entender a proposta da mediação, mister primeiramente considerar o conflito sob outras bases. No Direito Processual Civil, como esclarece Cândido Rangel Dinamarco, o conflito pode ser conceituado como "a situação existente entre duas ou mais pessoas ou grupos, caracterizado pela pretensão a um bem ou situação da vida e impossibilidade de obtê-lo". ${ }^{8}$

$\mathrm{Na}$ sociedade em geral, o conflito é visto tradicionalmente de maneira negativa, como disputa, luta, briga ou desentendimento. Desta forma, acredita-se que o litígio deva ser evitado ou removido, uma vez que possivelmente trará dor, sofrimento, insatisfação e perdas.

Entretanto, a mediação parte da ideia de que eliminar completamente os conflitos seria impossível, na medida em que o homem é um ser social e que, neste contato com o outro, desentendimentos vão necessariamente ocorrer. Assim, faz-se necessário aceitar o pressuposto da inevitabilidade dos conflitos.

Neste cenário, como esclarece Fernanda Tartuce, o conflito deve ser analisado de maneira interdisciplinar, ou seja, não apenas sob o ponto de vista jurídico, mas também sociológico, psicológico e filosófico. Sob este novo enfoque, o conflito mostra-se salutar para o crescimento e o desenvolvimento da personalidade dos envolvidos, uma vez que gera experiências e vivências valiosas. ${ }^{9}$

Assim, o conflito deve ser analisado sob um viés positivo, uma vez que é útil e necessário para o crescimento das pessoas envolvidas, além de conduzir a mudanças e inovações, desde que corretamente tratado. Portanto, é necessário desenvolver e aprender técnicas de tratamento adequado de conflitos, para que se extraia o que de positivo ele

DINAMARCO, Cândido Rangel. Instituições de direito processual civil. 7. ed. rev. São Paulo: Malheiros, 2013. v. 1. p. 120-121.

$9 \quad$ TARTUCE, Fernanda. Mediação nos conflitos civis. São Paulo: Método, 2008. p. 33. 
possa oferecer e para que sejam evitadas ou minoradas as perdas. Neste contexto, inserese a mediação.

\subsection{Conceito de Mediação}

A mediação pode ser definida como um procedimento voluntário e extrajudicial de resolução de conflitos, no qual um terceiro imparcial, o mediador, facilita o diálogo entre os mediados para que eles possam construir uma solução adequada ao caso. Existem variadas formas de mediar, mas todas envolvem técnicas de negociação e cooperação entre os envolvidos.

Na famosa obra Getting to Yes, os autores fornecem os subsídios para uma negociação satisfatória, tendente a um acordo, e que se traduz na maneira adequada de manejo do conflito. Em primeiro lugar, é preciso separar as pessoas do problema. Quando os envolvidos estão com raiva, tristes ou levam as questões para o lado pessoal, fica extremamente difícil lidar com o problema. ${ }^{10}$

Também é necessário, em um procedimento de mediação, focar nos interesses e não nas posições. O interesse é o que motiva as pessoas e normalmente está oculto sob a posição. Ou seja, a posição é o que uma pessoa decidiu, enquanto o interesse é o que a motivou a tomar aquela decisão. Desta forma, o real problema não está no conflito de posições, mas no conflito entre os desejos, necessidades e temores de cada um. ${ }^{11}$

Por exemplo, se eu tenho um conflito entre irmãos que assumiram a administração da sociedade empresária fundada pelo genitor, as posições serão o que eles afirmam querer, como o cargo de presidente. Todavia, um interesse, inicialmente oculto, pode ser o sentimento de rejeição de um dos filhos em relação ao pai, que acabou ficando alijado do empreendimento, e que agora tenta mostrar competência e poder.

Assim, para que a mediação seja bem-sucedida, faz-se necessário conseguir que as partes saiam de suas posições e mostrem seus interesses, pois são estes que devem ser tratados. Inclusive, para a satisfação de um mesmo interesse, comumente são possíveis mais de uma posição. Após identificados os interesses, as partes são capazes de criar opções que satisfaçam os seus interesses e proporcionem ganhos mútuos. ${ }^{12}$

10 FISHER, Roger; URY, William; PATTON, Bruce. Getting to yes. Negotiating an agreement without giving in. 2. ed. Nova York: Penguin Books, 1991. p. 13.

11 FISHER, Roger; URY, William; PATTON, Bruce. Getting to yes. Negotiating an agreement without giving in. 2. ed. Nova York: Penguin Books, 1991. p. 23-24.

12 FISHER, Roger; URY, William; PATTON, Bruce. Getting to yes. Negotiating an agreement without giving in. 2. ed. Nova York: Penguin Books, 1991. p. 31. 
Para a identificação dos interesses existem inúmeras técnicas, as quais, não obstantes sejam muito relevantes, extrapolam o objeto deste estudo. ${ }^{13}$ Tais técnicas devem ser aprendidas pelo mediador, terceiro responsável por aproximar as partes e promover o diálogo entre os mediados. Ou seja, a atividade de mediação não é algo intuitivo, como alguns pensam. Ao contrário, é um procedimento sério, complexo, e que envolve o aprendizado de técnicas específicas, de modo que o aspirante a mediador deve se submeter a cursos de capacitação com aulas teóricas e práticas.

A mediação, muito embora não tenha um procedimento padrão, normalmente se desenvolve por meio de algumas fases. Segundo Adolfo Braga Neto, em um primeiro momento há a abertura, fase informativa na qual o mediador esclarece aos mediados o que é a mediação e quais são suas regras. A segunda fase é a investigação, na qual o mediador se esforça para conhecer a inter-relação entre as partes, fazendo perguntas e franqueando a palavra aos mediados. É um momento crucial, devendo o mediador fazer o uso de todas as suas técnicas. Após, é formulada uma agenda, que funciona como pauta do trabalho, fixando os pontos que serão objeto de resolução. A quarta fase é a criação de opções, na qual os mediados são instados a criar ideias de solução, de maneira criativa, para poderem posteriormente debatê-las (brainstorming). Neste momento as opções são apresentadas sem crítica ou julgamento. Depois, o mediador auxiliará as partes na avaliação das opções e na escolha da opção. Ao final, o mediador ajuda na construção conjunta do termo final de mediação, no qual deve constar de maneira clara tudo aquilo que as partes consideraram relevante para a solução do conflito. ${ }^{14}$

13 A título ilustrativo, conforme consta na Cartilha de Mediação elaborada em 2009 pela Comissão de Mediação e Arbitragem de OAB/MG, são técnicas de mediação:

“1) Escuta ativa: a partir da linguagem verbal e não-verbal, o mediador decodifica o conteúdo da mensagem como um todo. Propicia a expressão das emoções, o alívio das tensões e assegura a quem está falando a sensação de que está sendo ouvido.

2) Parafraseamento: o mediador reformula a frase, sem alterar o sentido original, para organizar, sintetizar e neutralizar seu conteúdo.

3) Formulação de perguntas: o mediador faz perguntas para obter as informações necessárias à compreensão do conflito, possibilitar sua ressignificação e a identificação de alternativas viáveis.

4) Resumo seguido de confirmações: o mediador relata, de forma abreviada, aquilo que foi dito ou o que ocorreu na interação entre os mediandos. Permite que as partes observem como suas palavras ou ações foram registradas pelo mediador.

5) Caucus: o mediador encontra-se em separado com cada parte e pode testar potenciais opções identificadas para a realização de um acordo.

6) Brainstorming (tempestade de idéias): incentiva a criatividade quando os mediandos não conseguem, por si, levantar opções. É realizada inicialmente para gerar idéias sem críticas (falar aquilo que vem à mente, sem pensar) e, em seguida, analisar e selecionar as idéias mais valiosas.

7) Teste de realidade: o mediador busca uma reflexão realista dos mediandos sobre as propostas apresentadas por meio de parâmetros objetivos".

14 BRAGA NETO, Adolfo. Reflexões sobre a conciliação e a mediação de conflito. In: SALLES, Carlos Alberto de. (Org.). As grandes transformações do processo civil brasileiro: homenagem ao Professor Kazuo Watanabe. São Paulo: Quartier Latin, 2009. p. 487-508. p. 497. 
É necessário esclarecer que a mediação não visa pura e simplesmente ao acordo. Seu objetivo precípuo é estimular o diálogo cooperativo de modo a conduzir à satisfação dos interesses e necessidades das pessoas envolvidas no conflito. $\mathrm{O}$ acordo acaba sendo um resultado lógico do trabalho cooperativo das partes.

Ademais, ainda que não se chegue a um acordo em uma situação específica, espera-se que as partes tenham aprendido a lidar com seus conflitos de maneira positiva, dialógica e cooperativa, e que este aprendizado lhe seja útil em situações futuras. A mediação, portanto, insere-se em um contexto de cultura da pacificação em detrimento da litigiosidade, por meio do estímulo ao consenso e à autocomposição.

\subsection{Meio não adversarial}

A mediação é um meio não adversarial de solução de controvérsias. De acordo com Gladys Álvarez et alii, o sistema judicial é adversarial e formal, uma vez que o Estado detém o monopólio da coerção e pode impor as decisões judiciais por meio da ameaça de uma sanção. Ou seja, uma forma de violência estaria sempre embutida. Em contrapartida, na mediação, por meio da construção conjunta da solução, é possível agradar aos interesses de ambas as partes, verificando-se um ganha-ganha, de modo que é considerada um meio não adversarial de solução de controvérsias. ${ }^{15}$

Segundo Luis M. Brown, não apenas o processo em si de mediação é diferente dos meios adversariais como a jurisdição e a arbitragem. A maior diferença é a gama de soluções possíveis que podem ser construídas pelas partes. A solução na mediação leva em conta aspectos financeiros, pessoais e de qualidade de vida dos envolvidos, enquanto o julgamento por um tribunal geralmente não considera a seguinte questão: “as partes podem viver com este resultado?". ${ }^{16}$ Por este motivo, as soluções construídas em um processo de mediação são mais tendentes a agradar a todos os envolvidos e, consequentemente, possuem maiores chances de serem cumpridas.

Dadas as sensíveis diferenças entre os meios adversariais e não adversariais de solução de controvérsias, Janet Weinstein, a partir das ideias de Len Riskin, afirma que, para que advogados consigam se tornar mediadores, faz-se necessário alterar "o mapa filosófico do advogado". Este se baseia em duas proposições: as partes são adversárias, de modo que, se uma ganha a outra perde; e as disputas devem ser resolvidas pela aplicação,

15 ÁlVAREZ, Gladys Stella; HIGHTON, Elena Inés; JASSAN, Elías. Mediación y Justicia. Buenos Aires: Depalma, 1996. p. 36.

16 BROWN, Louis M. Arbitration-Mediation-Preventive Law: What is justice? Preventive Law Reporter, Denver, v. 10, n. 2, p. 2, June 1991. p. 2. 
por um terceiro, de alguma regra geral do Direito. Neste esquema, a situação das partes é vista de maneira atomística e várias relações não são consideradas. ${ }^{17}$

No mesmo sentido, Vítor Carvalho Lopes esclarece:

O advogado para exercer a função de mediador deve procurar entender toda a fenomenologia que se encontra em torno da mediação, isto é, os seus princípios informadores, o seu procedimento, os seus direitos e deveres no exercício desta função, os direitos e deveres das partes que se encontram em conflito, os seus objetivos, enfim, todos os seus contornos e sua metodologia, de maneira a compreender que, de fato, ela é um mecanismo de solução de disputas muito distinto da Jurisdição, método com o qual ele se encontra afeito, removendo com isso obstáculos a seu respeito e de sua efetiva utilização. ${ }^{18}$

Janet Weisntein, a partir de um projeto no qual apresentou aos alunos do curso de Direito da cidade de San Diego o processo de mediação, verificou ser necessário que os advogados expandam este mapa filosófico para incluir a ideia de que o conflito pode ser resolvido de maneira conjunta com a solução de necessidades particulares dos envolvidos, e que esta solução pode permitir que os dois lados satisfaçam suas necessidades. Com este estudo, Weisntein concluiu que mesmo os alunos que não se tornaram mediadores, deixaram o curso com atitudes renovadas sobre o papel do Direito e o papel deles como advogados. ${ }^{19}$

\subsection{Mediação X Conciliação}

É comum, até mesmo entre operadores do Direito, o tratamento da conciliação e da mediação como sinônimos. Ou então, não raras vezes, faz-se confusão entre estas duas formas de autocomposição, ignorando ou minorando a relevância dos pontos de distinção entre elas.

O novo Código de Processo Civil, nos parágrafos $2^{\circ}$ e $3^{\circ}$ do art. 165, acertadamente aponta critérios de distinção entre mediação e conciliação:

$\S 2$ O $\mathrm{O}$ conciliador, que atuará preferencialmente nos casos em que não houver vínculo anterior entre as partes, poderá sugerir soluções para o litígio, sendo vedada a utilização de

\footnotetext{
17 WEINSTEIN, Janet. Teaching Mediation in Law Schools: training lawyers to be wise. New York Law School Law Review, New York, v. 35, n. 199, p. 199-238, 1990. p. 202.

18 LOPES, Vítor Carvalho. Dos Mediadores. In: PINHO, Humberto Dalla Bernardina de. (Coord.). Teoria geral da mediação à luz do projeto de lei e do direito comparado. Rio de Janeiro: Lumen Juris, 2008. p. 69.

19 WEINSTEIN, Janet. Teaching Mediation in Law Schools: training lawyers to be wise. New York Law School Law Review, New York, v. 35, n. 199, p. 199-238, 1990. p. 237.
} 
qualquer tipo de constrangimento ou intimidação para que as partes conciliem.

$\S 3$ ㅇ $\mathrm{O}$ mediador, que atuará preferencialmente nos casos em que houver vínculo anterior entre as partes, auxiliará aos interessados a compreender as questões e os interesses em conflito, de modo que eles possam, pelo restabelecimento da comunicação, identificar, por si próprios, soluções consensuais que gerem benefícios mútuos.

Conforme se verifica nos parágrafos transcritos, a conciliação seria indicada para os casos em que não exista vínculo anterior entre as partes. Essa orientação existe porque a conciliação trabalha com o conflito objetivo, com valores quantificáveis, admitindo-se a barganha e a sugestão de soluções pelo conciliador. Desta forma, é um método indicado, por exemplo, para relações de consumo ou acidentes de trânsito.

Em contrapartida, a mediação seria reservada aos casos em que preexista vínculo entre as partes. Desta forma, o mediador trabalha o conflito subjetivo, lida com a autoestima e as emoções dos envolvidos. Busca-se uma negociação cooperativa de modo a preservar o relacionamento preexistente dos mediados. Por isso, a mediação, normalmente, por demandar do mediador um conhecimento mais aprofundado da relação entre as partes, tem uma duração maior que a da conciliação e é indicada para conflitos familiares, de vizinhança e societários.

Mais além, o mediador não pode fazer sugestões, devendo apenas auxiliar às partes no reestabelecimento do diálogo. Conforme elucida Alexandre de Freitas Câmara:

o mediador não pode propor soluções, limitando-se a, por meio de técnicas muito sofisticadas (e que exigem um treinamento muito específico), ajudar os litigantes a descobrir, por si próprios, as possíveis soluções para o conflito em que envolvidos. Diferentemente, o conciliador está autorizado a apresentar propostas, sugerindo soluções possíveis que podem ser acatadas pelos litigantes..$^{20}$

As semelhanças entre a mediação e a conciliação envolvem o fato de ambas serem formas de autocomposição de litígios, que prezam pelo diálogo e pela autonomia dos envolvidos, funcionando o terceiro como um agente que aproxima as partes, sem jamais julgar ou impor qualquer decisão.

Não obstante as semelhanças, não se pode olvidar que são mecanismos distintos, com técnicas diferentes e que são indicadas para situações também distintas.

20 CÂMARA, Alexandre Freitas. Mediação e conciliação na Res. 125 do CNJ e no Projeto de Código de Processo Civil. In: MENDES, Aluisio Gonçalves de Castro; WAMBIER, Teresa Arruda Alvim. (Org.) $O$ processo em perspectiva: Jornadas Brasileiras de Direito Processual - homenagem a José Carlos Barbosa Moreira. São Paulo: Revista dos Tribunais, 2013. p. 39-45. p. 41. 


\subsection{Incentivo à mediação: uma tendência}

Nos últimos anos têm se verificado a tendência, em diversos países, de estímulo à mediação, o que se dá muitas vezes pela edição de novas leis impondo sua observância em fase pré-processual ou apenas regulamentando o seu procedimento.

Nos Estados Unidos, segundo Rachel Wohl, especialista americana em resolução alternativa de disputas, a mediação foi formalizada na década de 1970 e, desde então, os métodos se desenvolveram a ponto de criar um mercado extrajudicial privado, formado por advogados, juízes especializados e mediadores profissionais. Segundo ela, à medida que se percebeu que era possível chegar a soluções pacíficas, de forma mais rápida, confidencial e altamente customizada, a própria população passou a preferir enfrentar a outra parte numa mesa de conciliação. As taxas de sucesso das conciliações, em nível nacional, chegam a $75 \% .^{21}$

Na Argentina, desde a década de 1990, são desenvolvidas iniciativas de estímulo à mediação. Para além de haver Programas de Mediação Escolar em nível primário e secundário, e de ter sido incluída disciplina sobre os meios alternativos de resolução de conflitos nos programas das faculdades, em 1996, por meio da Lei n. 24.573, adotou-se a mediação como etapa obrigatória prévia ao juízo de qualquer questão, exceto para as causas elencadas no art. $2^{\circ}{ }^{22}$ sendo facultativa para as demandas de execução e despejo. Esta lei contribuiu para a formação de uma nova cultura de solução de conflitos entre os argentinos. ${ }^{23}$

${ }_{21}$ CANÁRIO, Pedro. EUA optam por mediação para resolver conflitos. Revista Consultor Jurídico, São Paulo: [s.n.], jul. 2011. Disponível em: <http://www.conjur.com.br/2011-jul-02/mediacao-privada-primeiraopcao-resolver-conflitos-eua>. Acesso em: 31 out. 2015.

22 Articulo $2^{\circ}$ - El procedimiento de la mediación obligatoria no será de aplicación en los siguientes supuestos: 1. - Causas penales.

2. - Acciones de separación personal y divorcio, nulidad de matrimonio, filiación y patria potestad, con excepción de las cuestiones patrimoniales derivadas de éstas. El juez deberá dividir los procesos, derivando la parte patrimonial al mediador.

3. - Procesos de declaración de incapacidad y de rehabilitación.

4. - Causas en que el Estado Nacional o sus entidades descentralizadas sean parte.

5. - Amparo, habeas corpus e interdictos.

6. - Medidas cautelares hasta que se decidan las mismas, agotándose respecto de ellas las instancias recursivas ordinarias, continuando luego el trámite de la mediación.

7. - Diligencias preliminares y prueba anticipada.

8.- Juicios sucesorios y voluntarios.

9. - Concursos preventivos y quiebras.

10. - Causas que tramiten ante la Justicia Nacional del Trabajo.

23 LOS PACHECO, Denise Lorena. Situación de la mediación y el arbitraje en Argentina. In: VIANCAS, Juan Enrique Vargas; GÓMEZ, Francisco Javier Gorjón. (Coord.). Arbitraje y mediación en las Américas. Santiago: Centro de Estudios de Justicia de las Américas, 2006. p. 57-65. 
A partir de alguns estudos realizados após dez anos de vigência da Ley de Mediación y Conciliación da Argentina, verificou-se que as metas de descongestionamento do sistema e de redução do tempo de duração do processo foram alcançadas. Por exemplo, de abril de 1996 a agosto de 2005, dos 183.065 casos direcionados à mediação, apenas $35,07 \%$ retornaram ao sistema para continuação do processo judicial. ${ }^{24}$

Ainda na América Latina, no Equador e Uruguai a lei também impõe a mediação como primeira providência antes do litígio; a Colômbia tem legislação sobre mediação desde 1981; o Peru criou uma Association Peruana de Negocition, Arbitrage e Conciliación (APENAC) em 1994; o Chile tem legislação sobre arbitragem; e a mediação é praticada no Paraguai, México, Honduras, Porto Rico e Costa Rica. ${ }^{25}$

A União Europeia editou em 2008 a Diretiva da Mediação e, em 2013, a Diretiva sobre a Resolução Alternativa de Litígios de Consumo. Na primeira Diretiva constam algumas regras gerais sobre mediação, como a confidencialidade do procedimento e a possibilidade de execução judicial do acordo, exigindo-se que os Estados-membros incentivem a sua adoção por todos os meios. Destaca-se que as diretivas vinculam o Estado-membro destinatário quanto ao resultado a ser alcançado, mas deixa a cargo das instâncias nacionais a tarefa de regular a forma e o meio. ${ }^{26}$

$\mathrm{Na}$ Alemanha, já eram previstas e regulamentadas a arbitragem, a conciliação, o acordo obtido fora de um processo e a transação em processo perante um tribunal estatal. Em 2012, foi aprovada a Lei de Promoção da Mediação e dos Outros Métodos de Resolução Alternativa de Litígios Extrajudiciais, para incorporar ao direito alemão a Diretiva da Mediação europeia. ${ }^{27}$

De acordo com Neil Andrews, o crescimento da mediação em um contexto global se deve a seis fatores: a percepção de que os processos judiciais são imprevisíveis; fonte de despesas, ansiedade e atraso; oferece pouco espaço para a participação das partes;

${ }^{24}$ ÁLVAREZ, Gladys Stella. Hacia un cambio de paradigma cultural en resolución alternativa de disputas. El modelo de la "mediación prejudicial obligatoria, anexa o conectada con tribunales civiles y comerciales en Argentina". Diez años de experiencia. In: VARGAS VIANCOS, Juan Enrique; GORJÓN GÓMEZ, Francisco Javier. (Coord.) Arbitraje y mediación en las Américas. Santiago: Centro de Estudios de Justicia de las Américas, 2006. p. 29-37. p. 34.

25 DIAS, José Carlos de Mello. A mediação vista como forma de pacificação de conflitos. In: SALLES, Carlos Alberto de. As grandes transformações do processo civil brasileiro: homenagem ao Professor Kazuo Watanabe. São Paulo: Quartier Latin, 2009. p. 569-577. p. 574.

26 STÖBER, Michael. Os meios alternativos de solução de conflitos no direito alemão e europeu: desenvolvimento e reformas. Revista de Processo, São Paulo, v. 40, n. 244, p. 361-380, jun. 2015. p. 361380.

27 STÖBER, Michael. Os meios alternativos de solução de conflitos no direito alemão e europeu: desenvolvimento e reformas. Revista de Processo, São Paulo, v. 40, n. 244, p. 361-380, jun. 2015. p. 361380 . 
o julgamento assegura a vitória para apenas uma das partes; a ausência de confidencialidade dos tribunais e o fato de o contencioso ser uma "guerra privada". ${ }^{28}$

Desta forma, o Brasil vem se inserir nesta tendência contemporânea de incentivo à mediação e aos demais meios consensuais de solução de litígios.

\subsection{A regulamentação da mediação no Brasil}

O Código de Processo Civil de 1973 não regulamentava a mediação e, nem mesmo, chegava a fazer qualquer menção a ela em seu texto. O legislador de 1973 trouxe dispositivos, ainda que de maneira tímida, apenas no tocante à conciliação. Por exemplo, estabeleceu a exigência de uma audiência de conciliação no procedimento sumário (art. 227), regulamentou a audiência preliminar (art. 331) e a tentativa de conciliação no início da audiência de instrução e julgamento (art. 448). Todavia, apenas a conciliação conduzida pelo juiz foi regulamentada, estando ausente a disciplina de uma conciliação levada a efeito por um terceiro facilitador.

Os Juizados Especiais Cíveis e Criminais foram criados pela Lei n. 9.099 de 1995 com o objetivo de buscar, sempre que possível, a conciliação e a transação. Mais uma vez, a lei deixou de fora a mediação, que não é referida em nenhum momento no texto da lei. Todavia, já foi um grande avanço no incentivo dos mecanismos de autocomposição, uma vez que impôs a realização de uma audiência prévia de conciliação nas demandas de competência dos Juizados.

Em 1998, foi apresentado pela Deputada Zulaiê Cobra o primeiro projeto de lei institucionalizando a mediação paraprocessual, o PL n. 4.827. Este projeto foi resultado do trabalho da comissão instituída pelo Instituto Brasileiro de Direito Processual. Conforme consta na exposição de motivos, o projeto buscou atender ao clamor social de fortalecimento da vertente extrajudicial de resolução de controvérsias.

Todavia, conforme explica Ada Pellegrini Grinover, o Conselho Nacional de Justiça, na oportunidade, presidido pela Ministra Ellen Gracie, emitiu uma nota técnica desfavorável ao projeto utilizando-se do argumento de que a obrigatoriedade da mediação seria contrária ao espírito do instituto, a remuneração dos mediadores encareceria o processo, e a atribuição da função de mediador exclusivamente aos advogados seria reserva de mercado. Desta forma, o processo acabou sendo engavetado. ${ }^{29}$

\footnotetext{
28 ANDREWS, Neil. Mediação e arbitragem na Inglaterra. Revista de Processo, Brasília, v. 37, n. 211, p. 281316, set. 2012. p. 281.

29 GRINOVER, Ada Pellegrini. Conciliação e mediação endoprocessuais na legislação projetada. Revista Síntese. Direito Civil e Processual Civil, São Paulo. v. 13, n. 91, p. 71-92, set./out. 2014. p. 74.
} 
A primeira grande inciativa de estímulo à mediação foi a Resolução n. 125 do Conselho Nacional de Justiça de 2010, projeto do então conselheiro Kazuo Watanabe. Esta resolução buscou instituir a política judiciária nacional de tratamento adequado dos conflitos, e partiu da seguinte da constatação:

(...) a conciliação e a mediação são instrumentos efetivos de pacificação social, solução e prevenção de litígios, e que a sua apropriada disciplina em programas já implementados no país tem reduzido a excessiva judicialização dos conflitos de interesses, a quantidade de recursos e de execução de sentenças; ${ }^{30}$

Foi uma importante iniciativa na medida em que criou os Centros Judiciários de Solução de Conflitos e Cidadania nos Tribunais, bem como trouxe regulamentação acerca da capacitação de mediadores e conciliadores. Todavia, a matéria ainda carecia de regulamentação por lei. Desta forma, a primeira lei a contemplar a mediação foi o novo Código de Processo Civil, cujas disposições sobre o tema serão analisadas no tópico abaixo.

Pouco mais de três meses após a aprovação do novo CPC, foi promulgada e aprovada a Lei n. 13.140, de 26 de junho de 2015, que "dispõe sobre a mediação entre particulares como meio de solução de controvérsias e sobre a autocomposição de conflitos no âmbito da administração pública". ${ }^{31}$

No caso de eventual conflito entre as normas da Lei de Mediação e as normas do novo Código de Processo Civil, deverão prevalecer aquelas, uma vez que, conforme entendimento de Ada Pellegrini Grinover, trata-se de lei posterior que revoga a anterior e de lei especial que revoga a genérica. ${ }^{32}$

\section{Inovações do Novo Código de Processo Civil}

3.1. Audiência de Conciliação ou Mediação - art. 334

O novo Código de Processo Civil, em seu art. 334, impõe ao juiz, quando receber a petição inicial, o dever de marcar uma audiência de conciliação ou mediação. Assim, o réu é citado não para contestar o pleito inicial, mas para comparecer à audiência

30 BRASIL. Resolução n. 125 de 29 de novembro de 2010. Dispõe sobre a Política Judiciária Nacional de tratamento adequado dos conflitos de interesses no âmbito do Poder Judiciário e dá outras providências. Conselho Nacional de Justiça, Brasília, DF, 2010. Disponível em: <http://www.cnj.jus.br/busca-atosadm?documento $=2579>$.

31 BRASIL. Lei n. 13.140, de 26 de junho de 2015.

32 GRINOVER, Ada Pellegrini. Os métodos consensuais de solução de conflitos no novo CPC. In: BONATO, Giovanni. (Coord.) et al. O novo código de processo civil. Questões controvertidas. São Paulo: Atlas, 2015. p. 1-21. p. 1 . 
marcada. Esta audiência só não será realizada se ambas as partes manifestarem de maneira expressa o desinteresse na composição consensual, ou se não for admitida a autocomposição $\left(\S 4^{\circ}\right)$. Ou seja, basta o interesse de uma das partes para que a audiência se realize.

Inclusive, o não comparecimento de uma das partes à audiência de mediação ou conciliação será sancionado com multa de até dois por cento da vantagem econômica pretendida ou do valor da causa, revertida em favor do Estado, por ser considerado um ato atentatório à dignidade da justiça $\left(\S 8^{\circ}\right)$.

No tocante a esta multa por não comparecimento, mister esclarecer que a mediação deve ser sempre um procedimento voluntário. Uma suposta obrigatoriedade em mediar acabaria por frustrar a própria ideia de método consensual. Assim, a obrigatoriedade é apenas quanto ao comparecimento à audiência e, consequentemente, à tentativa de mediar. Porém, se a parte não quiser dar continuidade ao procedimento, não poderá ser constrangida a tanto.

De acordo com Humberto Theodoro Júnior et alii, a audiência inaugural induzirá a uma necessária mudança do comportamento não cooperativo e agressivo das partes. Conforme os autores, influenciará inclusive no modo de elaboração das petições iniciais, que deverão ser vistas como "uma atividade preparatória de um potencial acordo". ${ }^{33}$

Mais além, esta audiência de conciliação e mediação no início do processo vem trazer uma racionalidade inversa àquela normalmente empregada no contexto brasileiro, qual seja, negligenciar a fase inicial do procedimento e, após anos de tramitação, perceber que havia alguma nulidade ou falta de pressuposto que inviabilizavam toda a atividade processual. A ideia agora é empregar mais tempo e energia no início, para obter ao final uma atividade processual mais efetiva. ${ }^{34}$

Para viabilizar estas audiências iniciais, o novo Código de Processo Civil determina a criação de centros judiciários de solução consensual de conflitos e o desenvolvimento de programas que auxiliem e estimulem a autocomposição (art. 165). A criação destes centros, que também está prevista no art. 24 da Lei de Mediação, já era mencionada no art. $8^{\circ}$ da Resolução n. 125/2010 do CNJ, embora com outro nome.

Ainda, o novo Código de Processo Civil faculta a utilização de câmaras privadas de conciliação e mediação, devidamente inscritas em cadastro nacional e do

\footnotetext{
33 THEODORO JÚNIOR, Humberto; NUNES, Dierle; BAHIA, Alexandre Melo Franco; PEDRON, Flávio Quinaud. Novo CPC. Fundamentos e sistematização. Lei 13.105 de 16.3.2015. 2. ed. Rio de Janeiro: Forense, 2015. p. 242.

34 THEODORO JÚNIOR, Humberto; NUNES, Dierle; BAHIA, Alexandre Melo Franco; PEDRON, Flávio Quinaud. Novo CPC. Fundamentos e sistematização. Lei 13.105 de 16.3.2015. 2. ed. Rio de Janeiro: Forense, 2015. p. 248.
} 
Tribunal de Justiça (art. 167). A escolha do mediador pode ser livremente feita pelas partes, desde que ele esteja inscrito nos referidos cadastros (art. 168). Se as partes não quiserem escolher, o mediador será indicado pelo tribunal, segundo critérios aleatórios de distribuição dos casos.

A iniciativa do novo Código de Processo Civil de retirar do juiz a tarefa de tentar conciliar ou mediar as partes, segundo Daniel Amorim Assumpção Neves, é positiva, na medida em que nem sempre o juiz detém a técnica necessária para tanto e, mais além, poderia ser acusado de prejulgamento em uma eventual participação mais ativa na tentativa de obter o acordo. Assim, centros especializados em mediação e conciliação, com pessoas devidamente capacitadas e que não julgarão a causa em caso de não obtenção do acordo, parece ter sido realmente a melhor opção. ${ }^{35}$

O Código de Processo Civil também elenca os princípios que devem nortear a conciliação e a mediação, quais sejam, independência, imparcialidade, autonomia da vontade, confidencialidade, oralidade, informalidade e decisão informada (art. 166).

A independência significa que o mediador deve atuar com liberdade, sem pressões externas ou internas, podendo conduzir o procedimento da maneira como julgar mais conveniente. A imparcialidade consiste no dever de agir sem favoritismos ou inclinações para uma ou outra parte. A confidencialidade é o dever de manter o sigilo de todas as informações obtidas no procedimento, salvo autorização de ambas as partes ou violação da ordem pública e das leis. Ainda, o mediador não pode atuar como advogado de uma das partes e nem como testemunha do caso. A mediação também deve ser regida pelos princípios da oralidade e informalidade, uma vez que se trata de um procedimento sem regras fixas predefinidas, podendo as partes, no exercício da autonomia da vontade, definir as próprias regras procedimentais (art. 166, $\S 4^{\circ}$ ). Por fim, os mediados devem tomar decisões devidamente informados das consequências e das particularidades do caso, de modo a manifestar um consentimento livre de vícios.

Avalia-se como positiva a previsão legal de uma audiência preliminar de conciliação ou de mediação, conduzida por profissional capacitado, como forma de estímulo à autocomposição e como tentativa de resolução da controvérsia de maneira consensual e mais célere. O novo Código de Processo Civil dá um importante passo rumo à cultura de pacificação, de modo que são esperados resultados positivos a partir desta mudança, como aqueles obtidos na Argentina com previsão semelhante.

35 NEVES, Daniel Amorim Assumpção. Novo CPC. Código de Processo Civil. Lei 13.105/2015. Rio de Janeiro: Forense; São Paulo: Método, 2015. p. 31. 


\subsection{Mediadores}

No novo Código de Processo Civil, os mediadores passaram a ser considerados, no art. 149, como auxiliares da justiça, uma vez que recebem da lei o encargo de realizar atividades que buscam o mesmo fim do Poder Judiciário, qual seja, a paz social.

Para ser mediador, a pessoa deve preencher o "requisito de capacitação mínima, por meio de curso realizado por entidade credenciada", e solicitar a inscrição nos cadastros nacional e do Tribunal de Justiça (art. 167, $\S 1^{\circ}$ ). Este cadastro pode ou não ser precedido de concurso público (art. 167, $\S 6^{\circ}$ ). Ainda, o Tribunal pode optar por ter o seu próprio quadro de mediadores e conciliadores.

O Conselho Nacional de Justiça e o Ministério da Justiça são os órgãos responsáveis por estabelecer os parâmetros mínimos para a capacitação de mediadores. Neste sentido, o presidente da Comissão Permanente de Acesso à Justiça e Cidadania do CNJ, conselheiro Emmanoel Campelo, durante o $2^{\circ}$ Encontro do Fórum Nacional de Mediação e Conciliação (Fonamec), divulgou como parâmetros curriculares mínimos para a capacitação de conciliadores e mediadores a realização de curso teórico com quarenta horas/aula e um estágio prático supervisionado de cinquenta horas com atendimentos de casos reais. ${ }^{36}$

Ainda no tocante aos mediadores, mostra-se equivocada a vedação contida no art. $167, \S 5^{\circ}$, de que "conciliadores e mediadores judiciais cadastrados na forma do caput, se advogados, estarão impedidos de exercer a advocacia nos juízos em que desempenhem suas funções". ${ }^{37}$ A ideia parece ser evitar que as funções de mediador ou conciliador sejam utilizadas para captar clientela. Todavia, como bem esclarece Ada Pellegrini Grinover, para além de desestimular advogados a exercerem estas funções, "a regulamentação da conduta ética e das sanções que podem ser impostas ao terceiro facilitador é mais que suficiente para desencorajar qualquer iniciativa nesse sentido". ${ }^{38}$

36 FORMAÇÃO de mediadores inclui curso teórico e estágio com supervisor, fixa CNJ. Revista Consultor Jurídico, São Paulo: [s.n.], out. 2015. Disponível em: <http://www.conjur.com.br/2015-out-29/formacaomediadores-inclui-curso-teorico-estagio-define-cnj>. Acesso em: 31 out. 2015.

37 Destaca-se que no projeto da deputada Zulaiê Cobra, constava que o mediador judicial deveria ser necessariamente advogado. Alvo de críticas, por ser considerada reserva de mercado, esta disposição não consta no texto aprovado do novo CPC e nem na Lei de mediação. Foi com acerto que o legislador desvinculou a função de mediador da função de advogado. Na realidade, por mais que o advogado deva ter sempre uma postura pacificadora e conciliadora (art. $2^{\circ}$, parágrafo único do Código de Ética e Disciplina da $\mathrm{OAB}$ ), sua função não se confunde com a do mediador.

38 GRINOVER, Ada Pellegrini. Os métodos consensuais de solução de conflitos no novo CPC. In: BONATO, Giovanni. (Coord.) et al. O novo código de processo civil. Questões controvertidas. São Paulo: Atlas, 2015. p. 1-21. p. 11 . 
Mais além, o art. 172 do novo CPC estabelece que o mediador fica impedido, pelo prazo de um ano, de assessorar, representar ou patrocinar qualquer das partes, o que por si só já dificulta a possibilidade de aliciamento de clientes. Todavia, por mais que esta vedação de que o advogado atue no mesmo foro em que realiza a função de mediador não conste na Lei de Mediação, entende não ter havido revogação do dispositivo, por serem as leis complementares.

Acrescente-se que, na audiência prévia de mediação judicial, a presença do advogado é requisito obrigatório (art. 334, $\S 9^{\circ}$ ), enquanto na mediação extrajudicial a presença é facultativa. Todavia, se uma das partes estiver assistida por advogado na mediação extrajudicial, deve-se interromper o procedimento para que a outra parte também possa ser assistida (art. 10, parágrafo único, da Lei de Mediação).

O novo Código de Processo Civil atendeu a uma antiga demanda: a previsão legal expressa de remuneração do mediador, segundo tabela fixada pelo tribunal (art. 169). Deste modo, afasta-se a ideia de voluntariedade da mediação, que contribuía para o seu rebaixamento face a outros mecanismos de tratamento de conflitos, como a arbitragem. Mais além, a remuneração vai colaborar para a profissionalização dos mediadores. Tal remuneração não será devida se o tribunal tiver seu próprio quadro de mediadores concursados ou se o mediador aceitar realizar o trabalho de maneira voluntária.

O novo Código de Processo Civil não deixa claro quem deve arcar com os valores referentes a esta remuneração. Por outro lado, a Lei de Mediação, em seu art. 13, estabelece que deverá ser custeada pelas partes, sendo gratuita aos necessitados.

Outra disposição interessante é a determinação contida no parágrafo $2^{\circ} \mathrm{do}$ art. 169 de que as câmaras privadas de conciliação e mediação deverão atender gratuitamente alguns processos nos quais tenha sido deferida a justiça gratuita, como contrapartida ao credenciamento. É uma importante previsão legal no sentido de desonerar o Estado.

Por fim, os mediadores podem ser excluídos dos cadastros, por meio de processo administrativo, caso venham a agir com dolo ou culpa na condução da mediação sob sua responsabilidade ou violem qualquer dos deveres decorrentes do art. 166, $\S \S$ $1^{\circ}$ e $2^{\circ}$; ou ainda se atuarem em procedimento, apesar de impedidos ou suspeitos (art. 173). Não há previsão expressa dos casos de impedimento para o mediador, devendo ser aplicado, analogicamente, as regras de impedimento do juiz, conforme determina o art. $5^{\circ}$ da Lei de Mediação.

4. Lei n. $13.140 / 2015$

Enquanto o projeto do novo Código de Processo Civil tramitava no Congresso Nacional, foi apresentado pelo Senador Ricardo Ferraço o Projeto de Lei n. 7.169/2014, com o objetivo de regulamentar a mediação entre particulares e a composição 
de conflitos no âmbito da Administração Pública. Este projeto converteu-se na Lei n. 13.140 de 26 de junho de 2015 .

Em que pese esta nova lei ter sido promulgada e publicada posteriormente ao novo Código de Processo Civil, deve-se levar em conta que são diplomas normativos complementares e, portanto, devem ser interpretados em harmonia.

Uma diferença entre os dois diplomas concerne ao âmbito de abrangência, pois enquanto o Código de Processo Civil disciplina apenas a mediação processual, a Lei n. 13.150/2015 regulamenta também a mediação extrajudicial. Em seu art. $9^{\circ}$ estabelece que poderá funcionar como mediador extrajudicial qualquer pessoa capaz, devidamente capacitada para a função e que tenha a confiança das partes, independentemente de inscrição em qualquer tipo de conselho, entidade de classe ou associação.

A mediação extraprocessual é acordada pelas partes por meio de um contrato de prestação de serviços plurilateral, na medida em que conta com a participação das partes e do mediador. Muito embora seja disciplinada nos arts. 21 a 23 da nova lei, a grande maioria das regras têm caráter supletivo, na medida em que se reserva um amplo espaço à autonomia das partes na direção do procedimento.

Quando da apresentação do Projeto de Lei n. 7.169/2014, Ada Pellegrini Grinover e Kazuo Watanabe redigiram um documento apontando inúmeros problemas deste projeto de lei e evidenciando o seu descompasso com o projeto de novo CPC e com a Resolução n. 125 do CNJ. Algumas das críticas foram levadas em consideração, de modo que o texto final aprovado difere do originalmente apresentado.

Entre as críticas elaboradas pelos eminentes juristas e que não foram levadas em consideração, destaca-se a ausência de referência à conciliação e, consequentemente, à correta distinção entre os meios consensuais de resolução de conflitos. $\mathrm{O}$ argumento de que a conciliação já se encontraria disciplinada no ordenamento jurídico pátrio não poderia ser aceito na medida em que estava prevista apenas a conciliação conduzida pelo juiz, e não por um terceiro facilitador. ${ }^{39}$

Mais além, os autores entendem que o projeto seria restritivo, na medida em que o art. $4^{\circ}, \S 1^{\circ}$ teria contemplado apenas a mediação facilitativa, que na realidade seria conciliação, olvidando as diversas modalidades de mediação (transformativa, reflexiva, circular narrativa). ${ }^{40}$

39 GRINOVER, Ada Pellegrini. Conciliação e mediação endoprocessuais na legislação projetada. Revista Sintese. Direito Civil e Processual Civil, São Paulo. v. 13, n. 91, p. 71-92, set./out. 2014. p. 81.

40 GRINOVER, Ada Pellegrini. Conciliação e mediação endoprocessuais na legislação projetada. Revista Sintese. Direito Civil e Processual Civil, São Paulo. v. 13, n. 91, p. 71-92, set./out. 2014. p. 82. 
Ainda, a nova lei não menciona a sanção pecuniária para a parte que não comparecer à audiência prévia de conciliação e mediação, como faz o novo CPC no art. $334, \S 8^{\circ}$, como forma de incentivar os meios consensuais. ${ }^{41}$

A nova lei também desconsidera a autonomia da vontade dos mediados quando determina que "os mediadores não estarão sujeitos à prévia aceitação das partes" (art. 25). Inclusive, há contradição neste ponto com o novo CPC, que estabelece que "as partes podem escolher, de comum acordo, o conciliador, o mediador ou a câmara privada de conciliação e de mediação" (art. 168). ${ }^{42}$

Para além das críticas, a lei aprovada e que entrou em vigor em janeiro de 2016 traz algumas disposições semelhantes às do novo Código de Processo Civil e outras que lhe são complementares. Em relação às normas complementares, a lei impõe a obrigatoriedade de comparecimento à primeira reunião de mediação, quando houver previsão contratual de cláusula de mediação (art. $2^{\circ}, \S 1^{\circ}$ ), mas ressalva que "ninguém será obrigado a permanecer em procedimento de mediação" (art. $2^{\circ}, \S 2^{\circ}$ ), uma vez que a voluntariedade é da essência do procedimento.

Mais além, a nova lei disciplina, em linhas gerais, o procedimento de mediação nos arts. 14 a 20. Destacam-se os dispositivos que determina a suspensão do prazo prescricional durante o procedimento (art. 17, parágrafo único) e que estabelece que o termo final da mediação será título executivo extrajudicial ou, se homologado, judicial (art. 20, parágrafo único).

A mediação judicial está disciplinada de maneira específica nos arts. 24 a 29, nos quais se verifica a repetição das regras já previstas no novo Código de Processo Civil. De todo modo, quanto ao procedimento, reiteram-se os princípios de informalidade e autonomia das partes, de modo a existir ampla liberdade na condução do procedimento e adequação ao caso concreto.

Em relação ao mediador, esta nova lei acrescenta um requisito para sua capacitação, qual seja, a graduação há, pelo menos, dois anos em curso de ensino superior (art. 11). Segundo a acertada crítica de Ada Pellegrini Grinover, "trata-se de uma restrição irrazoável, que contraria toda a filosofia que está na base das técnicas de mediação. Existem excelentes mediadores, devidamente capacitados, que não se enquadram na exigência". ${ }^{43}$ Todavia, a lei é coercitiva e este critério deverá ser respeitado.

41 GRINOVER, Ada Pellegrini. Conciliação e mediação endoprocessuais na legislação projetada. Revista Síntese. Direito Civil e Processual Civil, São Paulo. v. 13, n. 91, p. 71-92, set./out. 2014. p. 82.

42 GRINOVER, Ada Pellegrini. Conciliação e mediação endoprocessuais na legislação projetada. Revista Síntese. Direito Civil e Processual Civil, São Paulo. v. 13, n. 91, p. 71-92, set./out. 2014. p. 83.

43 GRINOVER, Ada Pellegrini. Os métodos consensuais de solução de conflitos no novo CPC. In: BONATO, Giovanni. (Coord.) et al. O novo código de processo civil. Questões controvertidas. São Paulo: Atlas, 2015. p. 1-21. p. 10 . 
Acertadamente, a nova lei não reserva a mediação apenas para os direitos disponíveis, uma vez que mesmo os direitos indisponíveis admitem autocomposição no tocante à forma e aos prazos de cumprimento da obrigação. No caso dos direitos indisponíveis, mas transigíveis, o acordo deverá ser homologado pelo juiz, com oitiva do Ministério Público (art. $3^{\circ}$ ).

\section{Conclusão}

O direito processual brasileiro, seguindo a tendência mundial, já há muito vem tentado criar uma cultura de pacificação de conflitos e de incentivo aos meios não adversariais de solução de controvérsias, sobretudo da conciliação. Isso se verifica na Lei n. 9.099 de 1995, que criou os Juizados Especiais Cíveis e Criminais e em outros dispositivos esparsos da legislação processual.

Entretanto, o novo Código de Processo Civil e a Lei de Mediação vêm inovar na medida em que não apenas estimulam os meios complementares de resolução de controvérsias, mas criam toda uma estrutura processual que já abarca a conciliação e a mediação, tornando-as uma realidade inexorável. A partir da obrigatoriedade de uma audiência preliminar de conciliação e mediação em todos os processos, advogados, juízes, promotores, defensores e partes inevitavelmente tomarão conhecimento destes mecanismos e de suas vantagens.

A mediação não deve ser vista somente como meio de desafogar o Poder Judiciário, mas como um mecanismo adequado de resolução de conflitos, no qual os envolvidos são instados a construir soluções que entendam adequadas e que, por isso, tendem a ser mais efetivas. A redução do número de processos será consequência de uma mudança de cultura em prol de soluções consensuais e negociadas.

O novo Código de Processo Civil não se limita apenas a prever a realização de audiência de conciliação e mediação, mas se preocupa igualmente em determinar a criação de centros judiciários de solução consensual de conflitos, em regulamentar a profissão do mediador e em estabelecer os princípios informadores do procedimento. $\mathrm{Ou}$ seja, o legislador tentou se precaver de todas as formas para que a mediação aconteça de forma efetiva e não seja meramente um requisito formal como, muitas vezes, a conciliação foi tratada na prática judiciária brasileira.

Por certo, problemas existirão na implementação deste novo modelo. Podem haver dificuldades orçamentárias e de recursos para a criação destes centros judiciários de solução consensual de conflitos, sobretudo em pequenas comarcas; dificuldades operacionais para a gestão do cadastro de mediadores; bem como para a mudança de mentalidade em prol do consenso, por parte de operadores do direito e de jurisdicionados. 
Entretanto, as dificuldades não devem reduzir a importância do esforço ora empreendido, sobretudo face aos esperados benefícios, os quais já foram alcançados em outros países como a Argentina. Assim, vê-se com otimismo as alterações implementadas pelo novo Código de Processo Civil no tocante à mediação.

Por mais que seja ingênuo acreditar na mudança da cultura e da mentalidade tão somente em virtude da edição de uma lei, espera-se que, com o tempo e com a obtenção de bons resultados, a resistência e a desconfiança em relação aos meios consensuais de solução de controvérsias se arrefeça. Afinal, o acordo não é um meio menos nobre, não é uma derrota. Ao contrário, é uma forma de que todos saiam vencedores e de que se possa extrair o melhor dos conflitos.

Belo Horizonte, maio de 2016.

\section{Referências}

ÁLVAREZ, Gladys Stella. Hacia un cambio de paradigma cultural en resolución alternativa de disputas. El modelo de la "mediación prejudicial obligatoria, anexa o conectada con tribunales civiles y comerciales en Argentina". Diez años de experiencia. In: VARGAS VIANCOS, Juan Enrique; GORJÓN GÓMEZ, Francisco Javier. (Coord.) Arbitraje y mediación en las Américas. Santiago: Centro de Estudios de Justicia de las Américas, 2006. p. 29-37.

ÁLVAREZ, Gladys Stella; HIGHTON, Elena Inés; JASSAN, Elías. Mediación y Justicia. Buenos Aires: Depalma, 1996.

ANDREWS, Neil. Mediação e arbitragem na Inglaterra. Revista de Processo, Brasília, v. 37, n. 211, p. 281-316, set. 2012 .

BRAGA NETO, Adolfo. Reflexões sobre a conciliação e a mediação de conflito. In: SALLES, Carlos Alberto de. (Org.). As grandes transformações do processo civil brasileiro: homenagem ao Professor Kazuo Watanabe. São Paulo: Quartier Latin, 2009. p. 487-508.

BRASIL. Resolução n. 125 de 29 de novembro de 2010. Dispõe sobre a Política Judiciária Nacional de tratamento adequado dos conflitos de interesses no âmbito do Poder Judiciário e dá outras providências. Conselho Nacional de Justiça, Brasília, DF, 2010. Disponível em: <http://www.cnj. jus.br/busca-atos-adm?documento=2579>.

BROWN, Louis M. Arbitration-Mediation-Preventive Law: What is justice? Preventive Law Reporter, Denver, v. 10, n. 2, p. 2, June 1991.

CÂMARA, Alexandre Freitas. Mediação e conciliação na Res. 125 do CNJ e no Projeto de Código de Processo Civil. In: MENDES, Aluisio Gonçalves de Castro; WAMBIER, Teresa Arruda Alvim. (Org.) O processo em perspectiva: Jornadas Brasileiras de Direito Processual - homenagem a José Carlos Barbosa Moreira. São Paulo: Revista dos Tribunais, 2013. p. 39-45. 
CANÁRIO, Pedro. EUA optam por mediação para resolver conflitos. Revista Consultor Jurídico, São Paulo: [s.n.], jul. 2011. Disponível em: <http://www.conjur.com.br/2011-jul-02/mediacaoprivada-primeira-opcao-resolver-conflitos-eua>. Acesso em: 31 out. 2015.

COMISSÃO DE MEDIAÇÃO E ARBITRAGEM DA OAB/MG. Cartilha de Mediação. Belo Horizonte: Comissão de Mediação e Arbitragem OAB/MG, 2009.

CONSELHO NACIONAL DE JUSTIÇA. Justiça em números 2015: ano-base 2014. Brasília: CNJ, 2015.

DIAS, José Carlos de Mello. A mediação vista como forma de pacificação de conflitos. In: SALLES, Carlos Alberto de. As grandes transformações do processo civil brasileiro: homenagem ao Professor Kazuo Watanabe. São Paulo: Quartier Latin, 2009. p. 569-577.

DINAMARCO, Cândido Rangel. Instituições de direito processual civil. 7. ed. rev. São Paulo: Malheiros, 2013. v. 1.

FISHER, Roger; URY, William; PATTON, Bruce. Getting to yes. Negotiating an agreement without giving in. 2. ed. Nova York: Penguin Books, 1991.

FORMAÇÃO de mediadores inclui curso teórico e estágio com supervisor, fixa CNJ. Revista Consultor Jurídico, São Paulo: [s.n.], out. 2015. Disponível em: <http://www.conjur.com.br/2015out-29/formacao-mediadores-inclui-curso-teorico-estagio-define-cnj>. Acesso em: 31 out. 2015.

GRINOVER, Ada Pellegrini. Conciliação e mediação endoprocessuais na legislação projetada. Revista Síntese. Direito Civil e Processual Civil, São Paulo. v. 13, n. 91, p. 71-92, set./out. 2014.

. Os métodos consensuais de solução de conflitos no novo CPC. In: BONATO, Giovanni. (Coord.) et al. O novo código de processo civil. Questões controvertidas. São Paulo: Atlas, 2015. p. 1-21.

LOPES, Vítor Carvalho. Dos Mediadores. In: PINHO, Humberto Dalla Bernardina de. (Coord.). Teoria geral da mediação à luz do projeto de lei e do direito comparado. Rio de Janeiro: Lumen Juris, 2008.

LOS PACHECO, Denise Lorena. Situación de la mediación y el arbitraje en Argentina. In: VIANCAS, Juan Enrique Vargas; GÓMEZ, Francisco Javier Gorjón. (Coord.). Arbitraje y mediación en las Américas. Santiago: Centro de Estudios de Justicia de las Américas, 2006. p. 57-65.

NEVES, Daniel Amorim Assumpção. Novo CPC. Código de Processo Civil. Lei 13.105/2015. Rio de Janeiro: Forense; São Paulo: Método, 2015.

STÖBER, Michael. Os meios alternativos de solução de conflitos no direito alemão e europeu: desenvolvimento e reformas. Revista de Processo, São Paulo, v. 40, n. 244, p. 361-380, jun. 2015.

TARTUCE, Fernanda. Mediação nos conflitos civis. São Paulo: Método, 2008. 
THEODORO JÚNIOR, Humberto; NUNES, Dierle; BAHIA, Alexandre Melo Franco; PEDRON, Flávio Quinaud. Novo CPC. Fundamentos e sistematização. Lei 13.105 de 16.3.2015. 2. ed. Rio de Janeiro: Forense, 2015.

WATANABE, Kazuo. Política judiciária nacional de tratamento adequado dos interesses em conflito. Utilização dos meios alternativos de resolução de controvérsias. In: MENDES, Aluisio Gonçalves de Castro; WAMBIER, Teresa Arruda Alvim. (Org.) O processo em perspectiva: Jornadas Brasileiras de Direito Processual - Homenagem a José Carlos Barbosa Moreira. São Paulo: Revista dos Tribunais, 2013. p. 241-245.

WEINSTEIN, Janet. Teaching Mediation in Law Schools: training lawyers to be wise. New York Law School Law Review, New York, v. 35, n. 199, p. 199-238, 1990. 
